\title{
Seasonal infections and nutritional status
}

\author{
B Y NEVILLE F. SUTTLE \\ Moredun Research Institute, 408 Gilmerton Road, Edinburgh EH17 7JH
}

The purpose of the present paper is fourfold: first to draw attention to the enormous impact which seasonal infections by nematodes can have on the nutritional status and growth of ruminants, despite regular dosing with anthelmintic; second, to suggest a primary role of larval challenge as a source of those nutrient losses; third, to create awareness of the delays which may occur between seasonal infection and nutritional impact; fourth, to suggest new approaches to the reduction of parasite-induced malnutrition in infections, both seasonal and aseasonal, in animals and man.

\section{NEMATODE INFECTIONS AND NUTRITIONAL STATUS IN RUMINANTS}

Students of host-parasite relationships in ruminants have been fortunate in being able to study under carefully controlled conditions the effects of the continuous, moderate ('trickle') infections known to cause seasonal problems in the field. The nutritional consequences of such infections have been widely studied and recently reviewed at a symposium of this Society (Holmes, 1993; MacRae, 1993). Protein, energy and mineral metabolism are all perturbed by 'trickle' infection in numerous ways, beginning with depressed nutrient intake and compounded by impaired nutrient absorption and utilization. Nutrient supplementation not only restores muscle and bone growth but reduces worm burden so that enhanced natural immunity may contribute to the improvements in growth. Manipulation of nutrient (particularly protein) supply has been suggested as a means of limiting parasite-related losses in grazing animals (Poppi et al. 1990) and shown to be effective in lambs (Steel, 1994). However, none of the experimental studies has reproduced the sequences of seasonal infections by different species which are commonly experienced by grazing animals and as a result the nutritional impact of the parasite may have been underestimated.

\section{SEASONALITY OF NEMATODE INFECTIONS}

The seasonality of nematode infections is attributable to three main influences: first, temperature- and moisture-dependence of the first stage of the nematode life-cycles, i.e. the hatching of eggs deposited on pasture, their development into infective larvae and transmission onto herbage; second, the annual introduction of susceptible young at lambing (and kidding or calving); third, the relaxation of immunity in the adult around parturition which results in a rise in egg output, contaminating the pasture to be grazed by their 'naive' offspring. The coincidence of infected pasture and vulnerable grazing stock in spring perpetuates the infection. Furthermore, there will be a seasonal increase in the level of infection on pasture as a result of the phenomenal egg output of every female worm which attains maturity unless the cycle is broken. Nematode species vary in their climatic requirements for hatching and larval development, and cold-tolerant species are the first to establish. Grazing lambs in the UK are, thus, first affected by 

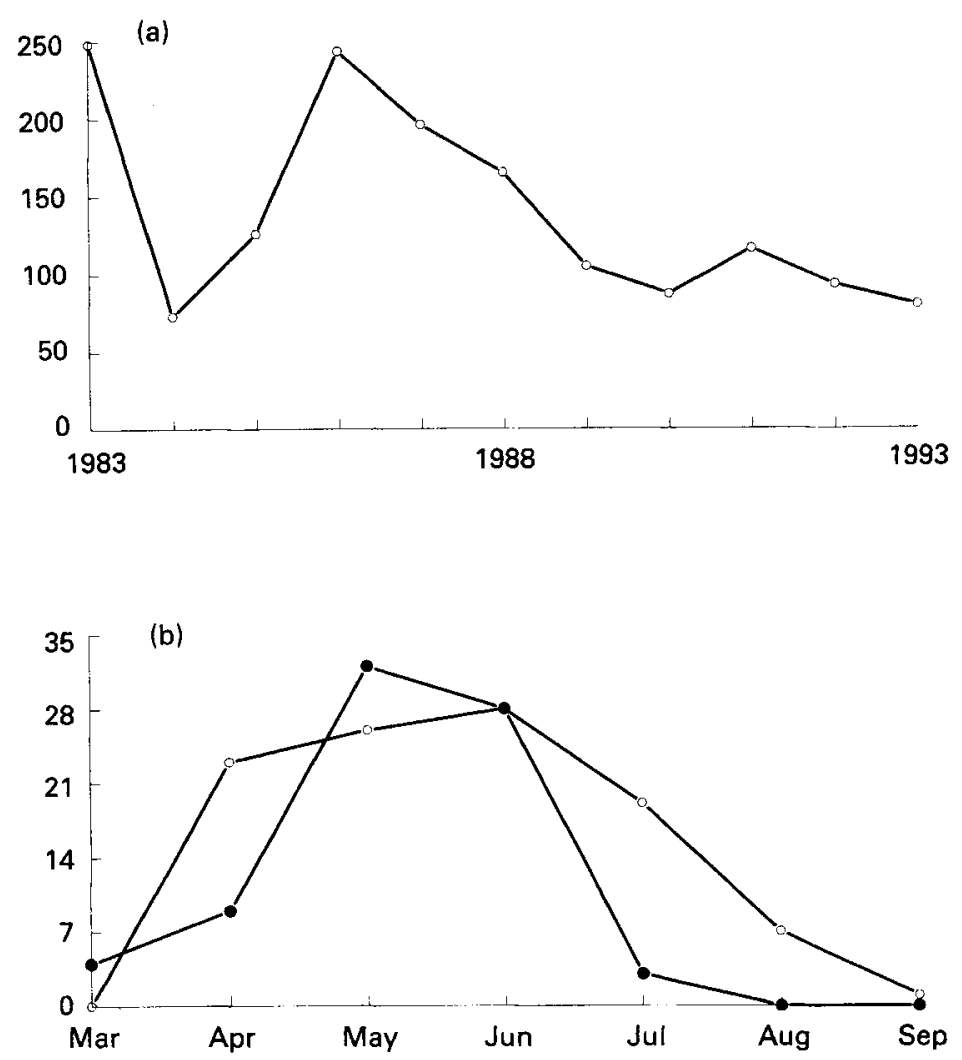

Fig 1. (a) Annual and (b) seasonal $(O, 1991 ;-0,1993)$ variation in the number of reported cases of nematodiriasis in the UK (source: VIDA 2 statistics, Central Veterinary Laboratory, Weybridge).

Nematodirus battus but the onset and seriousness of infection varies from year-to-year (Fig. 1) depending on spring weather conditions (Ollerenshaw \& Smith, 1966). In east Scotland the abomasal parasite Teladorsagia (Ostertagia) circumcincta does not become firmly established until July (e.g. Fig. 2), while the intestinal parasite Trichostrongylus vitrinus becomes dominant by late summer. The severity of these later infections is also weather dependent, heavy July rainfall being most influential (Ollerenshaw et al. 1978).

Infections in sheep are normally contained partly by the acquisition of natural immunity ('self-cure') by the developing lamb, partly by grazing management (e.g. grazing lambs on 'clean' pasture; Rutter et al. 1984) and partly by periodic removal of egg-laying adult worms with anthelmintic drenches. Natural immunity has two limitations: in addition to the relaxation of immunity around lambing, the immune response in the ewe and lamb may carry a high nutrient cost, as will be shown later. Anthelmintic efficacy can be limited by resistance on the part of the consumer or the nematode. Drug usage is prohibited, other than for critically sick animals, in organic farming systems of which there are an increasing number. Where drugs are used, repeated use of the same agent with incomplete efficacy can lead to the selection of anthelmintic-resistant populations (Jackson, 1993). Seasonal fluctuations in nematode populations on the 
(a)
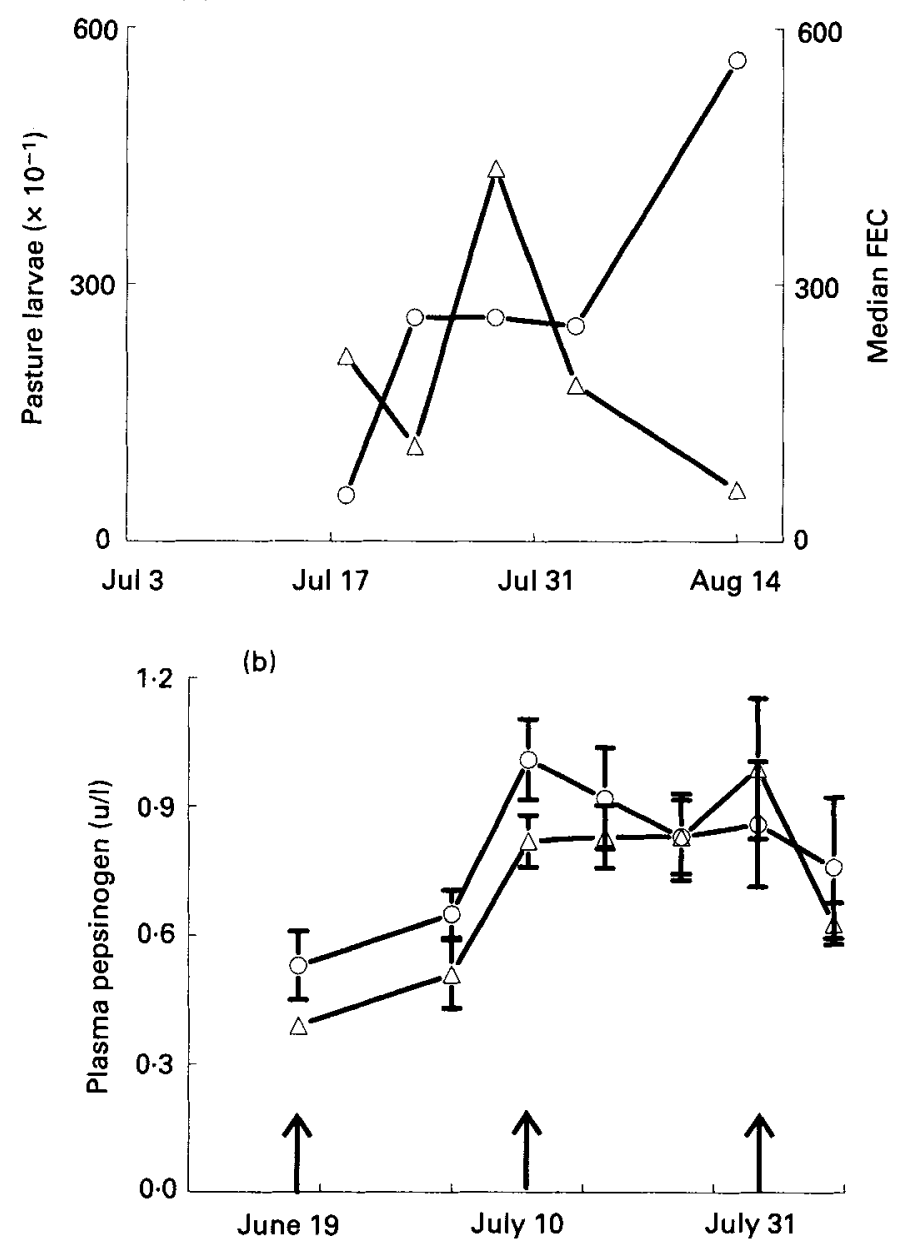

Fig. 2. (a) Contamination of pasture by strongylate larvae $(\triangle)$ other than Nematodirus battus usually reaches a peak in July and is followed by a rise in faecal egg count (FEC; $O$ ) which indicates the establishment of an adult worm burden (data from 1991 for Moredun Research Institute pastures): (b) a concurrent rise in plasma pepsinogen indicated invasion by species occupying the abomasal niche which was not prevented by three-weekly doses of anthelmintic. $(\bigcirc)$, Ivermectin; $(\Delta)$, no anthelmintic; $\uparrow$, ivermectin administered.

pasture and in the grazing animal can be predicted by modelling (for example, see Barnes \& Dobson, 1990) because the impact of the most influential variables are predictable, even the build up of anthelmintic resistance. However, the impact on health is less predictable because of the hitherto neglected importance of immature worms and the residual effects of early infections on the responses to later infections by different species.

\section{ANTHELMINTIC-UNRESPONSIVE DIARRHOEA (AUD) IN LAMBS}

Finnish Landrace (FL) lambs grazing pastures at Moredun Research Institute are affected each year, though to varying degrees, by a seasonal diarrhoea (Suttle, 1994). 

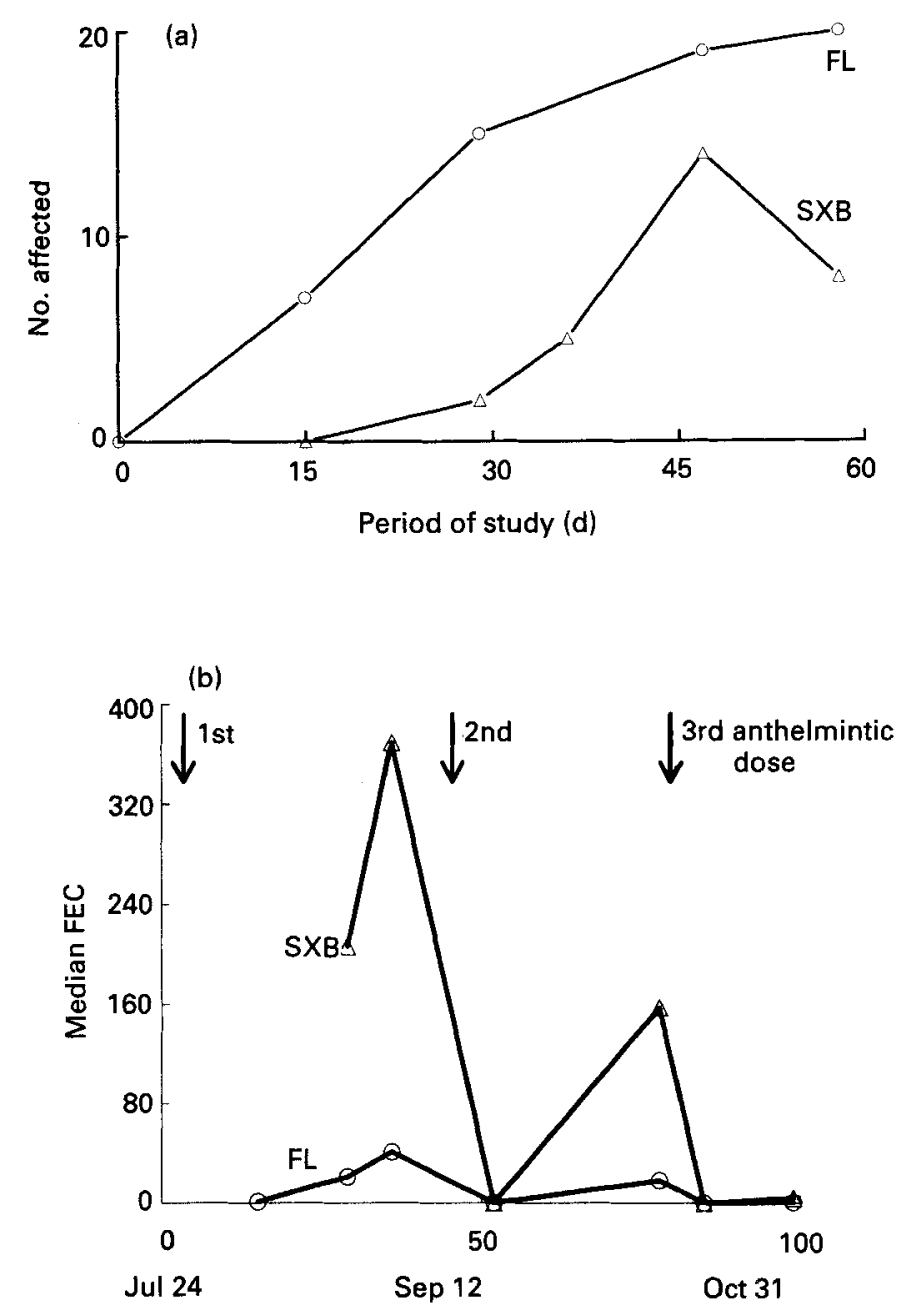

Fig. 3. (a) Diarrhoea developed faster in one breed (Finnish Landrace (FL; $O$ )) than another (Suffolk $x$ Scottish Blackface (SXB; $\triangle$ )) despite anthelmintic treatment, and (b) SXB developed the larger adult worm burden indicated by faecal egg count (FEC). A hypersensitive mucosal immune response to nematode infection in FL lambs is implicated as a cause of diarrhoea.

Treatments with anthelmintic or coccidiostat were ineffective and, therefore, the diarrhoea was thought to be of nutritional rather than infectious origin. Excessive consumption of a $\mathrm{Mg}$-rich mineral mixture and $\mathrm{Cu}$ deficiency were each investigated but found to be of only marginal importance (Suttle et al. 1994). Other breeds were believed to be less vulnerable to AUD and in the course of comparing FL lambs with those of another breed (Suffolk $\times$ Scottish Blackface (SXB)) strong evidence of nematode involvement was found (Suttle \& Brebner, 1994).

Fig. 3(a) illustrates the different rates of development of diarrhoea in the two breeds in the autumn of 1989 , FL being the earlier and the more affected. The diarrhoea coincided with a rise in faecal egg counts (FEC) for other strongyles ( $T$. circumcincta, $T$. vitrinus 


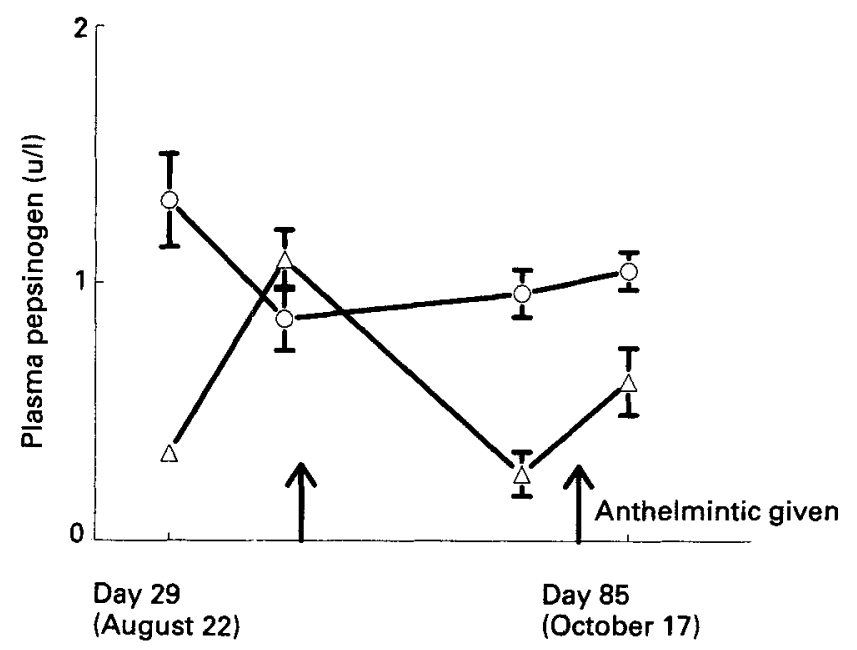

Fig. 4. Raised plasma pepsinogen (PP) $(>1.0 \mathrm{u} / \mathrm{l})$ values did not respond to anthelmintic treatment in a breed (Finnish Landrace, O) susceptible to diarrhoea (cf. Fig. 3(a)). Abomasal damage developed later and was anthelmintic responsive in a breed (Suffolk $\times$ Scottish Blackface, $\triangle$ ) less susceptible to diarrhoea. Failure of anthelmintic treatment to control diarrhoea may be linked to a failure to control larval damage of the abomasum.

and colubriformis, Haemonchus contortus, Oesophagostomum spp.; Fig. 3(b)), but the increases were barely noticeable in the more vulnerable breed. The rise in FEC indicated the development of an adult worm burden following continuous larval infection between doses of anthelmintic in SXB lambs. FL lambs faced the same larval challenge but must have mounted a more effective immune response which prevented most ingested larvae from becoming fecund. The association of diarrhoea with immunity suggests a hypersensitive response of the gut mucosa to larval infection. The disappearance of nematode eggs from the faeces immediately after dosing (Fig. 3(b)) confirms that anthelminticresistant strains of nematodes were not responsible for the lack of response to anthelmintic (ivermectin).

Larvae of species which invade the abomasum cause physical and physiological changes in the gastric mucosa which are seen as a rise in plasma pepsinogen (PP) concentrations (Coop et al. 1977). While FL lambs were able to prevent or delay the attainment of maturity by the invading abomasal parasite, Fig. 4 shows that abomasal changes were not controlled since PP values were far higher in FL than SXB lambs. Furthermore, the administration of anthelmintic reduced PP in SXB but not FL lambs. Larval re-infection probably renewed the stimulus to the abomasal mucosa in FL lambs before the immune response could intervene. Lack of response in PP to anthelmintic in the hypersensitive FL lamb is readily explained by the brief period (often as little as 2-3 d) over which larval killing capacity is retained after dosing. Before abomasal repair can become significant, following the removal of one worm population, the harmful mucosal changes are sustained by the next generation.

Clinically, AUD resembles 'July disease', a seasonal diarrhoea of lambs characterized by unresponsiveness to anthelmintic treatment (Watt, 1971). The two conditions probabily have a common cause (nematode infection) and the coincidence is important in 
Table 1. Relationships between pasture larval burden (PLB), live-weight gain ( $L W G)$ after weaning (in July), salivary sodium:potassium and plasma albumin in mid-August in lambs treated every 3-5 weeks with anthelmintic*

\begin{tabular}{cccccc}
\hline \hline & $\begin{array}{c}\text { PLB } \dagger \\
\text { (L3 larvae/kg } \\
\text { dry matter) }\end{array}$ & $\begin{array}{c}\text { LWG } \\
(\mathrm{g} / \mathrm{d})\end{array}$ & $\begin{array}{c}\text { Salivary } \\
\text { Na:K } \ddagger\end{array}$ & $\begin{array}{c}\text { Plasma } \\
\text { albumin } \neq \\
(\mathrm{g} / \mathrm{l})\end{array}$ & $n$ \\
\hline 1990 & 1706 & 88 & $11 \cdot 5$ & $23 \cdot 1$ & 12 \\
1991 & 674 & 150 & $21 \cdot 5$ & $29 \cdot 0$ & 17 \\
1992 & 4318 & 95 & $17 \cdot 0$ & $25 \cdot 6$ & 8 \\
1993 & 3905 & -20 & $13 \cdot 1$ & $21 \cdot 4$ & 12 \\
\hline
\end{tabular}

* Ivermectin in 1991-3; levamisole in 1990.

$\dagger$ Strongyles other than Nematodirus battus: pasture sampled between July 17 and August 14 .

¥ Samples taken in mid-August.

suggesting that AUD and the associated malnutrition are not confined to one breed (FL), locality (Edinburgh) or narrow season (see Fig. 3).

\section{NUTRITIONAL CONSEQUENCES OF ANTHELMINTIC-UNRESPONSIVE DIARRHOEA}

In subsequent experiments, anthelmintics were with held from a variable proportion of the lambs (from $25-70 \%$ ) and the timing of first treatment was delayed on one occasion (1993): the unintentional but fortuitous consequence was that level and pattern of infection of the pasture varied from year-to-year. The severity of AUD also varied and using lamb growth rate up to mid-August as a measure of early severity, the year of minimum AUD (1991) was clearly marked by a low pasture larval burden of strongyles (excluding $N$. battus; Table 1). Na status was monitored by analysing salivary samples for $\mathrm{Na}: \mathrm{K}$ and protein status by measuring plasma albumin. $\mathrm{Na}$ and protein status only approached normality when pasture larval burden and incidence of AUD were minimal (Table 1) suggesting a $\mathrm{Na}$ - and protein-losing enteropathy. Hypocupraemia was also found and positive correlations between $\mathrm{Na}: \mathrm{K}$ and plasma $\mathrm{Cu}$ within and between samplings (Suttle et al. 1994) suggest that larval-induced malabsorption affected microas well as macronutrients. However, the maximal severity of AUD in 1993 cannot be explained by the 'other strongyle' burden alone which was greater in 1992. Furthermore, anthelmintic-unresponsive damage to the abomasum occurred in the year of minimal incidence (Fig. 2), just as it had done in other years. Incidence of AUD and the malabsorptive sequelae was probably determined by responses to more than one species.

\section{ANTHELMINTIC-UNRESPONSIVE GROWTH RETARDATION (AUGR)}

Nematode infections can retard growth despite the removal of adult worms following drug administration or immune exclusion. In lambs continuously infected with an abomasal parasite ( $T$. circumcincta) for 14 weeks, administration of anthelmintic (fenbendazole) every 3 weeks restored only $30 \%$ of the reduction in growth rate (Coop et al. 1982). In untreated lambs, growth rate was not fully restored after the acquisition of natural immunity, although diarrhoea was characteristically absent during this single 
infection of the abomasum. In lambs continuously infected with an intestinal parasite ( $T$. colubriformis) for 34 weeks, FEC fell to zero between weeks 8 and 15 and growth ceased, but there was no subsequent catch-up growth following the 'self-cure' (Kimambo et al. 1988). In lambs grazing infected pastures, regular anthelmintic dosing did not eliminate growth retardation (McAnulty et al. 1982). These results suggest that the nutritional cost of meeting continuous larval challenges in naive or immune lambs retarded growth, although clinical signs of parasitic gastroenteritis (i.e. diarrhoea) were absent. Anthelmintics are more effective in preventing the build-up of infection on pasture than they are at protecting lambs from current infections.

\section{MIXED INFECTIONS: MALNUTRITIVE SYNERGISM}

The study of host responses to mixed infections of the gut is relatively recent and the general finding is that pathogenicity is enhanced, i.e. the combined effect is more than the sum of the separate infections. Mixed infections by Eimeria spp. (i.e. coccidia) and $N$. battus induced severe diarrhoea while separate infections induced only transient diarrhoea (Catchpole \& Harris, 1989). Combined nematode infections at abomasal and intestinal sites caused a similar increase in pathogenicity (Steel et al. 1982; Heath \& Connan, 1991). The synergisms probably have two nutritional components: first, an enhanced loss of appetite; second, impaired nutrient absorption and utilization (Sykes et al. 1988). Mucosal damage by species occupying distal sites probably prevents the recycling of water and nutrients secreted or lost in excess amounts at proximally infected sites. Impaired recycling of $P$ (Bown et al. 1989) and plasma protein (Bown et al. 1984) has been reported in mixed abomasal-intestinal infections. While abomasal infection induced $\mathrm{Na}$ efflux into the abomasum in experimentally infected lambs on a marginally Na-deficient diet, salivary Na:K was unaffected (N. F. Suttle and E. Ortolani, unpublished results), presumably because the $\mathrm{Na}$ was re-absorbed at uninfected distal sites (cf. Wilson \& Field, 1983). Grazing lambs with combined abomasal and intestinal infections, however, become Na-deficient (Oosterhuis et al. 1992).

\section{DELAYED EFFECTS OF SEASONAL INFECTIONS}

Experimental infections with two nematode species have always involved simultaneous challenges at uniform rates. In natural infections, the host is exposed to unsynchronized waves of infection by different species to which they become successively immune and synergisms may take different forms under such conditions. Yakoob et al. (1983) reported increases in albumin turnover and gastrointestinal plasma loss, along with increases in PP, when immune adult ewes were challenged continuously with mixed strongylate larvae. The changes were as marked as those seen previously when naive lambs were similarly challenged (Holmes \& MacLean, 1971). While the cause of malabsorption and inefficient nutrient utilization changed from the physical to the immunological and the culprit from partly adult to entirely larval nematode, nutritional outcome probably remained the same. In the field, lambs will normally have acquired substantial immunity to $N$. battus before they are challenged by later species, but this does not mean that $N$. battus is no longer important. Lambs may be called upon to mount an immune response to a late infection while showing hypersensitivity towards $N$. battus as a result of an earlier infection and any nutritional costs become superimposed. In the 
year of minimum AUD, the peak $N$. battus larval burden on pasture was abnormally late (July 24) and coincided with that for other strongyles (Suttle et al. 1994). There was no hypoproteinaemia and presumably no hypersensitivity at the time of the July challenge by abomasal parasites (cf. Fig. 2).

Other residual nutritional effects of infection are possible. For example, the disproportionately poor growth and nutritional status in FL lambs in 1993 (Table 1) may have been due to the withholding of anthelmintic treatment until June. By that time significant $N$. battus burdens had established (median FEC 680), hypoalbuminaemia was present and plasma albumin values continued to decline. The early infection clearly caused a protein-losing enteropathy which may have impaired both the development of immunity and the repair of mucosal damage, enhancing the nutritional impact of subsequent infections. The impact of pasture larval infections on the clinical and nutritional status of lambs, therefore, may not be a simple reflection of current level of challenge (cf. Table 1) nor predicted by current computer models which do not allow for synergism between species.

The impact of a seasonal parasitic infection on nutritional status and health may be delayed in other ways. Pathogenicity may increase if either the nutritive quality of the diet declines or the nutritional requirement of the host changes. In sub-tropical regions, a decline in pasture quality during the dry season may increase the problems caused by blood-sucking nematodes in the gut (Holmes, 1993). In such circumstances, anthelmintic administration is advisable, although the risk of re-infection has receded. Similarly, where feed supply has been restricted by drought, removal of parasites is necessary to make the most of scarce resources. Some anthelmintic drenches are ineffective against the arrested larval stages of abomasal parasites. These are found in autumn-winter and may represent an adaptation by the parasite to avoid the harsh winter climate. Arrested larvae are believed to contribute to chronic cachexia and ill-thrift in elk (Cervus elaphus), causing a condition known as the 'fading elk syndrome' (Waldrup \& Mackintosh, 1992). Seasonal increases in nutrient demand associated with the 'roar' or breeding season compound the problem which can be alleviated by the continuous delivery of anthelmintic from a rumen bolus. It is possible that by the autumn the presence of arrested larvae in FL lambs contributed to their loss of condition.

\section{PARASITES AND HUMAN MALNUTRITION}

In reviewing information on the effects of parasitic infection on metabolism and nutritional status in man, Lunn \& Northrop-Clewes (1993) were forced to draw heavily on studies with small-animal models of questionable relevance. The means by which parasites lowered nutritional status in non-ruminants were, nevertheless, essentially the same as those described in ruminants (Holmes, 1993; MacRae, 1993). Data relating directly to man were restricted to trials in which improvements in the growth of children were sought following the administration of anthelmintics. Improvements in growth were often small and Lunn \& Northrop-Clewes (1993) identified a number of factors which may have been responsible:

(1) re-infection after (or between) anthelmintic doses;

(2) mixed infections;

(3) chronic immune-inflammatory responses to re-infection;

(4) skewed distributions of worm burdens in the population. 
All these factors are also characteristic of AUD and AUGR in grazing lambs. The development of an experimental model for AUD, therefore, might advance understanding of the effects of gut parasites on the nutritional status of children in developing communities. There is, however, one important difference between parasitized lambs and children: for lambs, the nutrient supply from pasture would be adequate in the absence of parasites, whereas nutritional inadequacy may predominate in the village communities studied. The ability of parasites to restrict infant growth may only become apparent once direct dietary constraints have been lifted. In rats infected with Nippostrongylus brasiliensis, growth was retarded on a high but not on a low plane of nutrition (Lunn et al. 1988).

\section{FUTURE CONTROL METHODS}

In ruminants, hopes for the future have been placed on three control strategies for gastrointestinal nematode infections:

(1) artificial immunity, the development of molecular vaccines;

(2) natural immunity, the selection of genetically-resistant lines;

(3) sustained chemical attack, slowly-released or -metabolized drug regimens.

Each could facilitate the control of AUD and AUGR, but all have their problems. The quest for artificial or natural immunity against gut parasites might result in AUD by eliciting a hypersensitive mucosal response unless the larval challenge is first reduced. Both immunity goals are long-term prospects which may have to be met concurrently for contrasting nematode species to achieve full control of malnutritive synergisms. Acquisition of anthelmintic resistance by nematodes constantly threatens to undermine the improved chemical delivery approach. Because of these limitations, the serious threat posed by seasonal infections in grazing livestock is likely to remain well into the next century. In the short-term, improved control of AUD and AUGR in lambs might be obtained by seasonally adapted strategies: supplementing with rumen-escape protein during the first of the seasonal attacks (by $N$. battus) before weaning; allowing lambs to graze the less-infected top of the sward $(>40 \mathrm{~mm})$ ahead of the scavenging but immune ewe to reduce the second wave of infection by abomasal species after weaning. Effective earlier measures might allow lambs to be sold fat before exposure to heavily contaminated pasture in late summer-autumn. For man the nutritional penalty from nematode infections of the gut has yet to be quantified. Once this is done, the case for developing vaccines or slow-release devices for anthelmintics would become clearer.

\section{REFERENCES}

Barnes, E. H. \& Dobson, R. J. (1990). Population dynamics of Trichostrongylus colubriformis in sheep: computer model to simulate grazing systems and the evolution of anthelmintic resistance. International Journal for Parasitology 20, 823-831.

Bown, M. D., Poppi, D. P. \& Sykes, A. R. (1984). The effect of mixed infection on the site of plasma absorption in the small intestine. Canadian Journal of Animal Science 64, Suppl., 197-198.

Bown, M. D., Poppi, D. P. \& Sykes, A. R. (1989). The effects of concurrent infection of Trichostrongylus colubriformis and Ostertagia circumcincta on calcium, phosphorus and magnesium transactions along the digestive tract of sheep. Journal of Comparative Pathology 101, 11-20.

Catchpole, J. \& Harris, T. J. (1989). Interaction between coccidia and Nematodirus battus in lambs on pasture. Veterinary Record 124, 603-605. 
Coop, R. L., Sykes, A. R. \& Angus, K. W. (1977). The effect of a daily intake of Ostertagia circumcincta larvae on body weight, food intake and serum constituents in sheep. Research in Veterinary Science 23, 76-83.

Coop, R. L., Sykes, A. R. \& Angus, K. W. (1982). The effect of three levels of intake of Ostertagia circumcincta larvae on growth rate, food intake and body composition in growing lambs. Journal of Agricultural Science $90,247-255$.

Heath, M. F. \& Connan, R. M. (1991). Interaction of Ostertagia and Nematodirus species in sheep and potential of serum fructosamine determination in monitoring gastrointestinal parasitism. Research in Veterinary Science 51, 322-326.

Holmes, P. H. (1993). Interactions between parasites and animal nutrition: the veterinary consequences. Proceedings of the Nutrition Society 52, 113-120.

Holmes, P. H. \& MacLean, J. M. (1971). The pathophysiology of ovine ostertagiasis: a study of the changes in plasma protein metabolism following single infections. Research in Veterinary Science 12, 265-271.

Jackson, F. (1993). Anthelmintic resistance - the state of play. British Veterinary Journal 149, 123-138.

Kimambo, A. E., MacRae, J. C., Walker, A., Watt, C. F. \& Coop, R. L. (1988). The effect of prolonged subclinical infection with Trichostrongylus colubriformis on the performance and nitrogen metabolism of growing lambs. Veterinary Parasitology 28, 191-203.

Lunn, P. G., Northrop, C. A. \& Wainwright, M. (1988). Hypoalbuminaemia in energy-protein malnourished rats infected with Nippostrongylus brasiliensis (Nematoda). Journal of Nutrition 118, 121-127.

Lunn, P. G. \& Northrop-Clewes, C. A. (1993). The impact of gastrointestinal parasites on protein-energy malnutrition in man. Proceedings of the Nutrition Society 52, 101-111.

McAnulty, R. W., Clark, V. R. \& Sykes, A. R. (1982). The effect of clean pasture and anthelmintic frequency on growth rates of lambs on irrigated pastures. Proceedings of the New Zealand Society of Animal Production 42, 187-188.

MacRae, J. C. (1993). Metabolic consequences of intestinal parasitism. Proceedings of the Nutrition Society $\mathbf{5 2}$, $121-130$.

Ollerenshaw, C. B., Graham, E. G. \& Smith, L. P. (1978). Forecasting the incidence of parasitic gastroenteritis in England and Wales. Veterinary Record 103, 461-465.

Ollerenshaw, C. B. \& Smith, L. P. (1966). An empirical approach to forecasting the incidence of nematodiriasis over England and Wales. Veterinary Record 79, 536-540.

Oosterhuis, C., McLean, K. \& Suttle, N. F. (1992). Natural mixed nematode infections can induce sodium deficiency in grazing Finnish Landrace lambs. Proceedings of the Nutrition Society 51, 144A.

Poppi, D. P., Sykes, A. R. \& Dynes, R. A. (1990). The effect of endoparasitism on host nutrition - the implications for nutrient manipulation. Proceedings of the New Zealand Society of Animal Production 50, 237-243.

Rutter, W., Black, W. J. M., Fitzsimmons, J. \& Swift, G. (1984). A clean grazing system for sheep - its development and extension. Research and Development in Agriculture 1, 41-46.

Steel, J. W. (1994). Proceedings of Workshop on the Pathophysiology of Parasitic Infections at the 14th World Association for the Advancement of Veterinary Parasitology Conference, Cambridge. Veterinary Parasitology (In the Press).

Steel, J. W., Jones. W. O. \& Symons, L. E. A. (1982). Effects of a concurrent infection of Trichostrongylus colubriformis on the productivity and physiological and metabolic responses on lambs infected with Ostertagia circumcincta. Australian Journal of Agricultural Research 33, 131-140.

Suttle, N. F. (1994). Anthelmintic unresponsive diarrhoeas in lambs. Proceedings of the Sheep Veterinary Society (In the Press).

Suttle, N. F. \& Brebner, J. (1994). A putative role for nematode infection in an autumn diarrhoea of lambs which does not respond to anthelmintic treatment. Veterinary Record (In the Press).

Suttle, N. F., Brebner, J. \& Hoeggel, U. (1994). Problems in differentiating the roles of copper deficiency, magnesium excess and nematodiasis in a summer diarrhoea of lambs. Veterinary Record (In the Press).

Sykes, A. R., Poppi, D. P. \& Elliot, D. C. (1988). Effect of concurrent infection with Ostertagia circumcincta and Trichostrongylus colubriformis on the performance of growing lambs consuming fresh herbage. Journal of Agricultural Science 110, 531-541.

Waldrup, K. A. \& Mackintosh, C. G. (1992). Fading elk syndrome research. Proceedings of a Deer Course for Veterinarians: Deer Branch Course no. 9. New Zealand Veterinary Association, pp. 170-172. New Zealand: Methuen.

Watt, J. A. (1971). The Shepherd's Guide. Department of Agriculture and Fisheries Advisory Bulletin no. 9, p. 91. Edinburgh: H.M. Stationery Office. 
Wilson, W. D. \& Field, A. C. (1983). Absorption and secretion of calcium and phosphorus in the alimentary tract of lambs infected with daily doses of Trichostrongylus colubriformis or Ostertagia circumcincta larvae. Journal of Comparative Pathology 93, 61-71.

Yakoob, A., Holmes, P. H. \& Armour, J. (1983). Pathophysiology of gastrointestinal trichostrongyles in sheep: plasma losses and changes in plasma pepsinogen levels associated with parasite challenge in immune animals. Research in Veterinary Science 34, 305-309. 